Veenhof, C., Dekker, J., Bijlsma, J.W.J., Ende, C.H.M. van den

Influence of various recruitment strategies on the study population and outcome of a randomized

controlled trial involving patients with osteoarthritis of hip or knee.

Arthritis and Rheumatism: 53, 2005, nr. 3, p. 375-382

\begin{tabular}{l|l|}
$\begin{array}{l}\text { Postprint Version } \\
\text { Journal website }\end{array}$ & $\begin{array}{l}1.0 \\
\text { http://www3.interscience.wiley.com/cgi- } \\
\text { bin/accessdenied?ID=110507543\&Act=2138\&Code=4717\&Page=/cgi- }\end{array}$ \\
$\begin{array}{l}\text { bin/fulltext/110507543/PDFSTART } \\
\text { Pubmed link }\end{array}$ & $\begin{array}{l}\text { http://www.ncbi.nlm.nih.gov/entrez/query.fcgi?cmd=Retrieve\&db=pubmed\&dop } \\
\text { t=Abstract\&list uids=15934129\&query hl=11\&itool=pubmed docsum }\end{array}$ \\
\hline DOI & \begin{tabular}{l} 
10.1002/art.21171 \\
\hline
\end{tabular}
\end{tabular}

Supported by a grant from the Health Care Insurance Board.

1 Cindy Veenhof, PT, MSc, Cornelia H. M. van den Ende, PT, PhD: Netherlands Institute for Health Services Research, Utrecht, The Netherlands;

2 Joost Dekker, PhD, MSc: Institute for Research in Extramural Medicine, VU Medical Centre Amsterdam, Amsterdam, The Netherlands;

3 Johannes W. J. Bijlsma, MD, PhD: University Medical Center Utrecht, Utrecht, The Netherlands.

Address correspondence to Cindy Veenhof, PT, MSc, NIVEL, PO Box 1568, 3500 BN Utrecht, The Netherlands. E-mail: c.veenhof@nivel.nl.

\title{
Study Population and Outcome of a Randomized Controlled Trial Involving Patients With Osteoarthritis of the Hip or Knee
}

\author{
CINDY VEENHOF, ${ }^{1}$ JOOST DEKKER, ${ }^{2}$ JOHANNES W. J. BIJLSMA, ${ }^{3}$ AND CORNELIA H.
} M. VAN DEN ENDE ${ }^{1}$

Objective. To examine the effect of 2 different recruitment methods on the characteristics of participants with osteoarthritis (OA) of the hip or knee and on the efficacy of an exercise program.

Methods. In a clinical trial on the effectiveness of exercise therapy in OA of the hip or knee, 2 groups of patients were recruited: one group through referrals by physiotherapists (PT group, $n=110$ ) and one group invited by newspaper articles (NP group, $n=90)$. At baseline, demographic, clinical, and psychosocial data were collected and compared between the 2 groups using chi-square and Student's t-tests. After 13 weeks of exercise therapy and followup assessments at weeks 39 and 65, the main outcome measures (pain, physical function, and global perceived effect) were assessed and compared by multiple regression analysis.

Results. The NP group reported less pain and tiredness at baseline, although more joints were affected with osteoarthritis. The PT group scored higher on the scale 'powerfulothers' of locus of control. After adjusting for baseline differences, the effect of treatment after 13, 39, and 65 weeks was comparable for both groups for all outcome measures.

Conclusion. Recruitment method affects clinical characteristics and physical functioning of patients recruited for the study. A mix of recruitment strategies does not seem to affect treatment outcome, on the condition that adjustments are made for baseline differences.

\section{INTRODUCTION}

To conduct a clinical trial in primary care, recruitment of a sufficient number of study participants is among the most challenging aspects. Various recruitment strategies are used for 
clinical trials, including referrals by physicians and physiotherapists, advertisements, and mailings. Different recruitment sources may target different types of patients and the recruitment method can influence the results of studies on the effectiveness of a treatment. For example, one may speculate that advertisement preferentially attracts patients whose symptoms are not severe enough for them to seek medical care. The effect of various recruitment strategies (telephone survey versus a media campaign) on the types of subjects entered into a primary prevention clinical trial was investigated by King et al (1). Few differences between recruitment sources were found for demographic variables (weight, marital status, number of persons in household, interest in making health changes), but counter to expectations, no differences were found in subsequent exercise adherence rates.

Recruitment strategy may affect clinical and psychosocial characteristics of the patient sample, which in turn may affect treatment outcome. In osteoarthritis (OA) of the hip or knee, loss of muscle strength (2-5), obesity (6,7), decreasing educational status (8), use of passive coping styles (such as worrying, catastrophizing, and avoidance of physical activity) (9-11), helplessness $(7,8)$, and radiographic evidence $(3,4)$ are associated with both pain and limitations of activities, which are the primary outcome measures of clinical trials of patients with OA (12). How- ever, the influence of these factors on the efficacy of interventions has been investigated in only a few studies. Sex, age, race, degree of obesity, muscle strength, range of motion (ROM), level of disabilities, and passive pain coping strategies were shown not to influence treatment outcome $(13,14)$. Limited evidence was found of beneficial effects in patients without radiographic OA, in patients with reports of recent onset, and in patients who complied with exercise therapy (13).

In the present study, we examined the effect of 2 recruitment strategies on the characteristics of patients with OA of the hip or knee and on the efficacy of an exercise program in these patients. The first population was recruited through participating physiotherapists referred by general practitioners (GPs). Difficulties in recruiting sufficient subjects led to the use of a second recruitment strategy. The second population responded to local newspaper articles about the study. Patients responding to the newspaper were hypothesized to have less severe symptoms and to use a more active coping style compared with patients referred by a physiotherapist. Furthermore, it was hypothesized that differences in patient characteristics do not influence the efficacy of exercise therapy on primary outcome measures.

\section{MATERIALS AND METHODS}

\section{Study population.}

To answer the research questions, data from a randomized clinical trial were used. In the randomized clinical trial, 2 interventions for patients with OA of the hip or knee were compared. The intervention group was treated with exercise therapy integrated with the concept of graded activity $(15,16)$ given in intermittent sessions (called GRADIT). The treatment of the control group consisted of exercise therapy according to the Dutch guideline for physiotherapists for hip or knee OA (17). Data were collected at baseline and at 13 weeks, 39 weeks, and 65 weeks.

All treatments were given by physiotherapists in primary care. A total of 87 physiotherapists were trained to participate in the study. To avoid exchange of information between participating physiotherapists about the 2 different treatments, randomization was performed at the level of the participating physiotherapeutic practices.

Two hundred patients with hip or knee OA participated in the trial. Inclusion criteria of eligible patients were OA of the hip or knee according to the clinical criteria of the American College of Rheumatology $(18,19)$. Exclusion criteria were as follows: other pathology explaining the symptoms; symptoms in $<10$ of 30 days; treatment for these symptoms with exercise therapy in the preceding 6 months; $<50$ or $>80$ years of age; indication for hip or knee replacement within 1 year; contraindication for exercise therapy; inability to understand the Dutch language; and a high level of physical function, operationalized on a score of $<2$ on the walking ability and physical function sections of the Algofunctional Index (AFI) (20). Data of all 200 patients were used in this study. 
Veenhof, C., Dekker, J., Bijlsma, J.W.J., Ende, C.H.M. van den

Influence of various recruitment strategies on the study population and outcome of a randomized

controlled trial involving patients with osteoarthritis of hip or knee.

Arthritis and Rheumatism: 53, 2005, nr. 3, p. 375-382

\section{Recruitment methods.}

Patients were recruited for the trial GRADIT in 2 ways, through physiotherapists and through articles in local newspapers. The selection procedure of both recruitment strategies is described.

Patients recruited by physiotherapists (PT group) were selected in the period November 2001 through May 2003. Patients, who had been referred to participating physiotherapists, received oral and written information about the study from the physiotherapist. If the patient was interested, the physiotherapist contacted the research team to enroll the patient. Then, the research team contacted the patient by phone explaining the goal and implications of participating in the study and performing a first screening. If patients were eligible, a final screening visit at home was planned.

Recruitment through the newspaper (NP group) took place in the period November 2002 through May 2003. Articles about the benefit of exercise therapy in patients with OA of the hip or knee and information about the GRADIT study were published in local newspapers of several villages and small towns. The total circulation was about 300,000. Interested patients were asked to contact the research team by telephone. The selection procedure consisted of several steps.

1) Interested patients contacted the research team by telephone. The research team gave oral information. Patients were screened by telephone and were instructed to consult their GP about the treatment by a physiotherapist, the study, and a referral to a physiotherapist. Furthermore, written information about the treatment and implications of participating in the study was sent to them.

2) Two weeks later, eligible patients were contacted to check the opinion of their GP. If patients were still motivated to participate and referral to a physiotherapist was obtained, an appointment for a screening at home was made.

3) A research assistant visited the patients and performed the final screening. In case of inclusion, the patients chose a physiotherapist participating in the trial. The patients were not aware of the kind of intervention (experimental or control) the physiotherapists would give.

If patients were eligible and willing to participate, informed consent was signed and baseline measurements were performed.

\section{Outcome assessment.}

Demographic and clinical data were collected for each patient including age, sex, education, height, weight, location of osteoarthritis, duration of symptoms, and the presence of other chronic disorders. The body mass index was calculated for each patient (weight/height ${ }^{2}$ ). X-rays of the hip and knee were scored by a rheumatologist following a standardized procedure according to the Kellgren and Lawrence scale $(21,22)$. The Kellgren and Lawrence scale consists of 5 degrees: 0 , no OA; 1 , doubtful OA; 2, minimal OA; 3, moderate OA; and 4, severe OA.

Impairments in body functions. Patients rated their pain and tiredness at the moment of assessment and in the past week on a visual analog scale (VAS). Pain was assessed with the pain subscale of the Western Ontario and McMas- ter Universities Osteoarthritis Index (WOMAC) (23) and the pain section of the AFI (20). Stiffness was assessed with the stiffness subscale of the WOMAC. Measurements of assisted active ROM of the hip and knee bilaterally were performed with a goniometer according to a standardized protocol (24). Isometric muscle strength of the hip and knee bilaterally was measured with the MicroFet, a handheld dynamometer (25). The measurements of both ROM and muscle strength were repeated 2 times, the average score was used in the analyses.

Limitations of activities. Limitations were assessed with the physical function subscale of the WOMAC and the walking ability and physical function sections of the AFI. Global perceived effect (GPE) was assessed by patients on an 8 -point scale ( $1=$ vastly worsened; $8=$ completely recovered) (26). The ability to walk was measured by a 5-meter walking time test. The level of physical activity was determined by the Short Questionnaire to Assess Health Enhancing Physical Activity (27).

Psychosocial variables. Coping was assessed by the Pain Coping Inventory (28). Locus of control was measured by the Multidimensional Health Locus of Control questionnaire, reflecting 
Veenhof, C., Dekker, J., Bijlsma, J.W.J., Ende, C.H.M. van den

Influence of various recruitment strategies on the study population and outcome of a randomized controlled trial involving patients with osteoarthritis of hip or knee.

Arthritis and Rheumatism: 53, 2005, nr. 3, p. 375-382

3 dimensions of health locus of control beliefs: internality, powerful others, and chance $(29,30)$.

Patients rated their social support using the Social Support Scale (31).

Health-related quality of life. Quality of life was assessed with the Short Form 36 (SF-36) checklist (32).

All used instruments are reported to be reliable and valid. Primary outcome measures were pain (VAS and WOMAC), physical function (WOMAC), and global perceived effect, according to the core set of outcome measures of clinical trials with patients with OA, defined by Outcome Measures in Rheumatology Clinical Trials III (12). All measurements were obtained at baseline, 13 weeks, 39 weeks, and 65 weeks by 3 trained research assistants who were blinded for the recruitment condition (physiotherapist or newspaper) and the assigned treatment.

\section{Statistical analysis.}

The analysis was performed on an intention-to-treat basis. At 13 weeks, 39 weeks, and 65 weeks, loss to followup was 8, 30, and 21, respectively. The ratings of GPE were dichotomized as improved ("completely recovered," "very much improved," and "much improved") versus not improved ("slightly improved," "not changed," "slightly worsened,” "much worsened,” and "vastly worsened") and odds ratios (OR) were calculated to test differences between groups. Since GPE could not be determined at baseline, GPE was assessed only at weeks 13, 39, and 65. Comparisons of the baseline scores between the 2 recruitment groups were conducted using chisquare tests for frequency data and Student's $t$-tests for continuous data. Change scores were calculated by subtracting the baseline scores from the posttreatment scores (weeks 13, 39, and 65 ) and were compared for the 2 recruitment groups using Student's $t$-test. To adjust for baseline differences, multiple linear regression analyses were performed with the change scores as dependent variable, type of recruitment as independent variable, and the baseline scores of each outcome measure as covariates. In addition, pain at the moment of assessment, location of OA, and duration of symptoms (i.e., the most important variables on which the groups differed at baseline; see Results), were included as covariates. $P$ values $<0.05$ were considered statistically significant.

\section{RESULTS}

\section{Participant flow.}

Figure 1 shows the flow of participants through the stage of patient enrollment. During the study, 136 patients with hip or knee OA were recruited by participating physiotherapists. Of these 136 patients, 110 patients participated in the study; 23 patients were not eligible after screening by phone; during the final screening, an additional 3 patients were excluded. A total of 395 patients contacted the research team after publication of articles in local newspapers, of which 205 patients were interested in participating after receiving oral information. Of these 205 patients, 97 were excluded after screening by phone and after reading written information and consulting the general practitioner. Of the remaining 108 patients, an additional 18 patients were excluded during the final screening, leading to a total of 90 patients of the NP group participating in the trial. In summary, $81 \%$ of the patients recruited by physiotherapists appeared to fulfill the inclusion criteria, compared with $23 \%$ of the patients who contacted the research group after reading local newspaper articles.

\section{[ FIGURE 1 ]}

The 13-week followup measurement was completed by 192 patients. Reasons for withdrawal and loss to followup were surgery of patient $(n=3)$, comorbidity $(n=2)$, loss of motivation (n $=1)$, family circumstances $(n=1)$, and death of patient $(n=1)$. At 65 weeks, 179 patients completed the followup. Reasons for loss to followup were loss of motivation $(n=9)$, comorbidity $(n=5)$, family circumstances $(n=2)$, patient moving residence $(n=2)$, costs of treatment $(n=1)$, adverse effects of treatment $(n=1)$, and death of patient $(n=1)$. 
Veenhof, C., Dekker, J., Bijlsma, J.W.J., Ende, C.H.M. van den

Influence of various recruitment strategies on the study population and outcome of a randomized

controlled trial involving patients with osteoarthritis of hip or knee.

Arthritis and Rheumatism: 53, 2005, nr. 3, p. 375-382

\section{Demographic and clinical data.}

The demographic and clinical characteristics of the patients in the 2 recruitment groups differed in 4 variables (Table 1). The NP group consisted of more patients with both knee and hip OA and of more patients with 2 affected sides of knee OA. Furthermore, the NP group reported a higher duration of symptoms of both the knee and hip. No differences, however, were found in radiographic evidence of OA. Finally, level of education was higher in the NP group.

\section{[ TABLE 1$]$}

\section{Impairments in body functions and limitations of activities.}

The severity of the most important symptoms, namely pain, stiffness, and tiredness, and the restrictions in physical function of the patient are presented in Table 2. The PT group reported more pain and tiredness compared with the NP group. No significant differences were found in ROM, muscle strength of hip and knee, or pain section of AFI (data not presented). Concerning physical function, no differences were found in either WOMAC score, AFI, or in time spent on physical activity, although the NP group performed the 5-meter walking test faster than the PT group.

\section{[ TABLE 2 ]}

\section{Psychosocial variables.}

The psychosocial characteristics of the 2 recruitment groups were similar (Table 3). No differences were found in coping styles, social support, or quality of life (assessed with SF-36). One exception is a higher score of the PT group on the powerful-others scale of the locus of control scale.

\section{[ TABLE 3 ]}

\section{Effect of treatment.}

Table 4 presents the results of the effectiveness of treatment after 13 weeks and 65 weeks. After 13 weeks, in both groups almost $40 \%$ of the patients rated themselves as improved on dichotomized GPE, with no differences between the groups (OR 0.96, 95\% confidence interval $0.5,1.7$ ). The physical function score (WOMAC) improved significantly within both groups (6.6 points in the PT group versus 5.2 points in the NP group). The difference between the PT group and NP group was not significant. The same pattern was observed for the scores on pain: statistically significant improvement within groups, but differences between groups were not significant. One exception was pain scored on the WOMAC scale. The PT group improved significantly more compared with the NP group. After adjusting for the baseline differences in pain (VAS at assessment), localization of OA, duration of symptoms, and the baseline score of the pain scale of WOMAC, all differences between the PT and NP groups were not significant.

\section{[ TABLE 4 ]}

The analyses of data at 39 and 65 weeks yielded similar results. The results of the effectiveness of treatment after 65 weeks are presented in Table 4. Compared with baseline, all outcome measures improved significantly within groups, but differences between groups were not found, with the exception of VAS pain at assessment. Again, the PT group improved more compared with the NP group, but after adjusting for baseline differences no significant differences were found. 


\section{DISCUSSION}

Several strategies have been used to recruit patients for clinical trials involving patients with OA of the hip or knee. The present study is the first to evaluate the influence of recruitment methods (physiotherapist and newspaper) on the study population and the efficacy of interventions in patients with OA. Patients recruited by a physiotherapist reported more pain and tiredness, needed more time to walk 5 meters, and scored higher on the powerful-others scale of locus of control. In contrast, the NP group was higher educated, consisted of more patients with multiple affected joints, and reported a higher duration of symptoms. Only small differences were found in the effectiveness of treatment, which disappeared after adjustment for baseline differences.

Different recruitment methods appear to attract different subjects. We hypothesized that patients responding to a newspaper have less severe symptoms and use a more active coping style compared with patients referred by a physiotherapist. As expected, the NP group reported less severe symptoms and limitations of the OA, although more joints were affected by OA. A possible explanation is that the NP group has learned to cope with the pain and limitations due to $\mathrm{OA}$ and are less inclined to consult GPs or physiotherapists for these symptoms. This conclusion is confirmed by the higher score of the PT group on the locus of control scale powerful others. No differences, however, were found in coping style.

As hypothesized, the differences between the 2 groups did not influence the effectiveness of the treatment on the primary outcome measures pain, physical function, and GPE. We only found a small difference in effect on the WOMAC pain scale (at 13 weeks) and VAS pain at assessment (at week 65), which disappeared after differences between both groups (pain at baseline [VAS], localization of OA, duration of symptoms, and WOMAC pain baseline score) were taken into account while analyzing the effects of treatment. Our results confirm the findings of King et al (1) on the effect of recruitment method on types of subjects entered into a primary prevention trial. King et al found that there were few differences between recruitment sources for demographic variables, but these differences did not influence the effect of the intervention. In conclusion, our study included a more heterogeneous group of patients with OA of the hip or knee by using different recruitment sources. The heterogeneity of the study population did not influence the efficacy of the intervention.

The question arises which is the most efficient way to recruit patients for trials in primary care concerning hip or knee OA. Some research has been done about the most successful methods for recruiting adults with OA, but the results seem to be contradictory. According to Spencer et al (33), the most successful methods for enrolling participants with OA were through recruitment letters and television coverage. Others concluded that recruiting patients with OA through a local newspaper article was more efficient compared with recruiting participants via general practice (34). In contrast, Maurer et al (35) found physician referrals from affiliated clinics more effective than, for example, advertisements. One has to deliberate the advantages and disadvantages of each method to choose the best strategy. In our trial, publishing articles in local newspapers was a more successful method for recruiting patients with OA, which is in line with the study of Davey et al (34). In a period of 6 months, 90 patients were enrolled in the study, whereas the physiotherapists enrolled 110 patients in 18 months. However, to recruit 1 patient by newspaper took a lot more effort and time per patient from the investigators. This was due to the more extensive selection procedure for this group and the high number of ineligible persons who contacted the researchers. Only $23 \%$ of the persons who were admitted through local newspapers participated in the study, as opposed to $81 \%$ of the patients who were recruited by physiotherapists. Differences in costs involved with the 2 strategies were not assessed. This may influence the choice of a specific recruitment method. Unfortunately, many clinical trials have to cope with a severe delay in patient inclusion, as described in Lasagna's law (36). The results of this study justify the use of a mix of recruitment strategies in studies on the effect of OA interventions in primary care. This can improve and quicken the inclusion of patients in clinical trials.

In conclusion, the results of our study suggest that a mix of recruitment strategies can be used to study the effectiveness of exercise therapy in patients with OA of the hip or knee. Each 
Veenhof, C., Dekker, J., Bijlsma, J.W.J., Ende, C.H.M. van den

Influence of various recruitment strategies on the study population and outcome of a randomized controlled trial involving patients with osteoarthritis of hip or knee.

Arthritis and Rheumatism: 53, 2005, nr. 3, p. 375-382

recruitment strategy attracts subjects from different segments of the target community, which increases the generalization of the results of a clinical trial.

\section{ACKNOWLEDGMENTS}

The authors thank the physiotherapists and patients for participating in this study. We wish to express our gratitude to M. F. Pisters, C. H. Holdinga, C. Truschel, M. A. J. E. Biemans, A. C. M. Verheul, A. Holdinga, and M. N. Spies for their contribution to the data collection.

\section{REFERENCES}

1. King AC, Harris RB, Haskell WL. Effect of recruitment strategy on types of subjects entered into a primary prevention clinical trial. Ann Epidemiol 1994;4:312-20.

2. Dekker J, Tola P, Aufdemkampe G, Winckers M. Negative affect, pain and disability in osteoarthritis patients: the mediating role of muscle weakness. Behav Res Ther 1993;31: 2036.

3. McAlindon TE, Cooper C, Kirwan JR, Dieppe PA. Determinants of disability in osteoarthritis of the knee. Ann Rheum Dis 1993;52:258-62.

4. Madsen OR, Bliddal $H$, Egsmose $C$, Sylvest J. Isometric and isokinetic quadriceps strength in gonarthrosis: inter-relations between quadriceps strength, walking ability, radiology, subchondral bone density and pain. Clin Rheumatol 1995;14: 308-14.

5. Steultjens MP, Dekker J, van Baar ME, Oostendorp RA, Bijlsma JW. Muscle strength, pain and disability in patients with osteoarthritis. Clin Rehabil 2001;15:331-41.

6. Jordan JM, Luta G, Renner JB, Linder GF, Dragomir A, Hochberg MC, et al. Self-reported functional status in osteoarthritis of the knee in a rural southern community: the role of sociodemographic factors, obesity, and knee pain. Arthritis Care Res 1996;9:273-8.

7. Creamer $P$, Lethbridge-Cejku M, Hochberg MC. Factors associated with functional impairment in symptomatic knee osteoarthritis. Rheumatology (Oxford) 2000;39:490-6.

8. Creamer P, Lethbridge-Cejku M, Hochberg MC. Determinants of pain severity in knee osteoarthritis: effect of demographic and psychosocial variables using 3 pain measures. J Rheumatol 1999;26:1785-92.

9. Sullivan MJ, Stanish W, Waite $H$, Sullivan M, Tripp DA. Catastrophizing, pain, and disability in patients with softtissue injuries. Pain 1998;77:253-60.

10. Evers AW, Kraaimaat FW, Geenen R, Bijlsma JW. Psychosocial predictors of functional change in recently diagnosed rheumatoid arthritis patients. Behav Res Ther 1998;36:179- 93.

11. Van Lankveld W, Naring G, van 't Pad-Bosch P, van de Putte L. Behavioral coping and physical functioning: the effect of adjusting the level of activity on observed dexterity. $J$ Rheumatol 1999;26:1058-64.

12. Bellamy N, Kirwan J, Boers M, Brooks P, Strand V, Tugwell P, et al. Recommendations for a core set of outcome measures for future phase III clinical trials in knee, hip, and hand osteoarthritis: consensus development at OMERACT III. J Rheumatol 1997;24:799-802.

13. Van Baar ME, Dekker J, Bijl D, Oostendorp RA, Voorn TB, Bijlsma JW. Exercise therapy in patients with osteoarthritis of hip or knee: outcome in specific subgroups of patients. In: van Baar ME. Effectiveness of exercise therapy in osteoarthritis of hip or knee. Utrecht: NIVEL; 1998. p. 55-74.

14. Ettinger WH Jr, Burns R, Messier SP, Applegate W, Rejeski WJ, Morgan T, et al. A randomized trial comparing aerobic exercise and resistance exercise with a health education program in older adults with knee osteoarthritis: the Fitness Arthritis and Seniors Trial (FAST). JAMA 1997;277:25-31.

15. Lindstrom I, Ohlund C, Eek C, Wallin L, Peterson LE, Fordyce WE, et al. The effect of graded activity on patients with subacute low back pain: a randomized prospective clinical study with an operant-conditioning behavioral approach. Phys Ther 1992;72:279-93.

16. Lindstrom I, Ohlund C, Eek C, Wallin L, Peterson LE, Nachemson A. Mobility, strength, and fitness after a graded activity program for patients with subacute low back pain: a randomized prospective clinical study with a behavioral therapy approach. Spine 1992;17:641-52.

17. Vogels EM, Hendriks HJ, van Baar ME, Dekker J, Hopman- Rock M, Oostendorp RA, et al. KNGF-richtlijn voor het fysiotherapeutisch handelen bij patie"nten met artrose van heup en/of knie. Amersfoort: KNGF; 2001. 
Veenhof, C., Dekker, J., Bijlsma, J.W.J., Ende, C.H.M. van den

Influence of various recruitment strategies on the study population and outcome of a randomized controlled trial involving patients with osteoarthritis of hip or knee.

Arthritis and Rheumatism: 53, 2005, nr. 3, p. 375-382

18. Altman R, Alarcon G, Appelrouth D, Bloch D, Borenstein D, Brandt K, et al. The American College of Rheumatology criteria for the classification and reporting of osteoarthritis of the hip. Arthritis Rheum 1991;34:505-14.

19. Altman R, Asch E, Bloch D, Bole G, Borenstein D, Brandt K, et al. Development of criteria for the classification and reporting of osteoarthritis: classification of osteoarthritis of the knee. Arthritis Rheum 1986;29:1039-49.

20. Lequesne MG, Mery C, Samson M, Gerard P. Indexes of severity for osteoarthritis of the hip and knee: validation: value in comparison with other assessment tests. Scand J Rheumatol Suppl 1987;65:85-9.

21. Kellgren JH, Lawrence JS. Radiological assessment of osteoarthrosis. Ann Rheum Dis 1957;16:494-502.

22. Ravaud P, Dougados M. Radiographic assessment in osteoarthritis. J Rheumatol 1997;24:786-91.

23. Bellamy N, Buchanan WW, Goldsmith CH, Campbell J, Stitt L. Validation study of WOMAC: a health status instrument for measuring clinically-important patient-relevant outcomes following total hip or knee arthroplasty in osteoarthritis. J Orth Rheumatol 1988;1:95-108.

24. Norkin CC, White DJ. Measurement of joint motion: a guide to goniometry. Philadelphia: FA Davis Company; 1986.

25. Bohannon RW. Muscle strength testing with hand-held dynamometers. In: Admundsen LR, editor. Muscle strength testing: instrumented and non-instrumented systems. New York: Churchill Livingstone; 1990. p. 69-88.

26. Van der Heijden GJ. Shoulder disorder treatment: efficacy of ultrasoundtherapy and electrotherapy. Maastricht, The Netherlands: University Press Maastricht; 1996.

27. Wendel-Vos GC, Schuit AJ, Saris WH, Kromhout D. Reproducibility and relative validity of the short questionnaire to assess health-enhancing physical activity. J Clin Epidemiol 2003;56:1163-9.

28. Kraaimaat FW, Bakker A, Evers AW. Pijncoping-strategiee"n bij chronische pijnpatie"nten: De ontwikkeling van de Pijn- Coping-Inventarisatielijst (PCI). Gedragstherapie 1997;30: 185201. In Dutch.

29. Wallston KA, Wallston BS, DeVellis R. Development of the multidimensional health locus of control (MHLC) scales. Health Educ Monogr 1978;6:160-70.

30. Winefield HR. Reliability and validity of the health locus of control scale. J Pers Assess 1982;46:614-9.

31. Feij JA, Doorn CD, van Kampen D, van den Berg PT, Resing WC. Sensation seeking and social support as moderators of the relationship between life events and physical illness; psychological distress. In: Winnubst JA, Maes S, editors. Lifestyle stress and health. Leiden: DSWO Press; 1992. p. 285-302.

32. Ware JE Jr, Sherbourne CD. The MOS 36-item short-form health survey (SF-36). I. Conceptual framework and item selection. Med Care 1992;30:473-83.

33. Spencer AC, Kinne S, Belza BL, Ramsey S, Patrick DL. Recruiting adults with osteoarthritis into an aquatic exercise class: strategies for a statewide intervention. Arthritis Care Res 1998;11:455-62.

34. Davey R, Edwards SM, Cochrane T. Recruitment strategies for a clinical trial of communitybased water therapy for osteoarthritis. Br J Gen Pract 2003;53:315-7.

35. Maurer BT, Moreno SI, Pickard AR, Wurst BE, Norden DK, Schumacher HR Jr. A comparison of recruitment methods for an osteoarthritis exercise study. Arthritis Care Res 1995;8: 161-6.

36. Cramer JA. Patient recruitment and compliance issues in clinical trials. In: French JA, Dichter MA, Leppik IE, editors. New antileptic drug development: preclinical and clinical aspects. Amsterdam: Elsevier Science Publishers BV; 1993. p.211-22. 
Veenhof, C., Dekker, J., Bijlsma, J.W.J., Ende, C.H.M. van den

Influence of various recruitment strategies on the study population and outcome of a randomized controlled trial involving patients with osteoarthritis of hip or knee.

Arthritis and Rheumatism: 53, 2005, nr. 3, p. 375-382

\section{TABLES AND FIGURES}

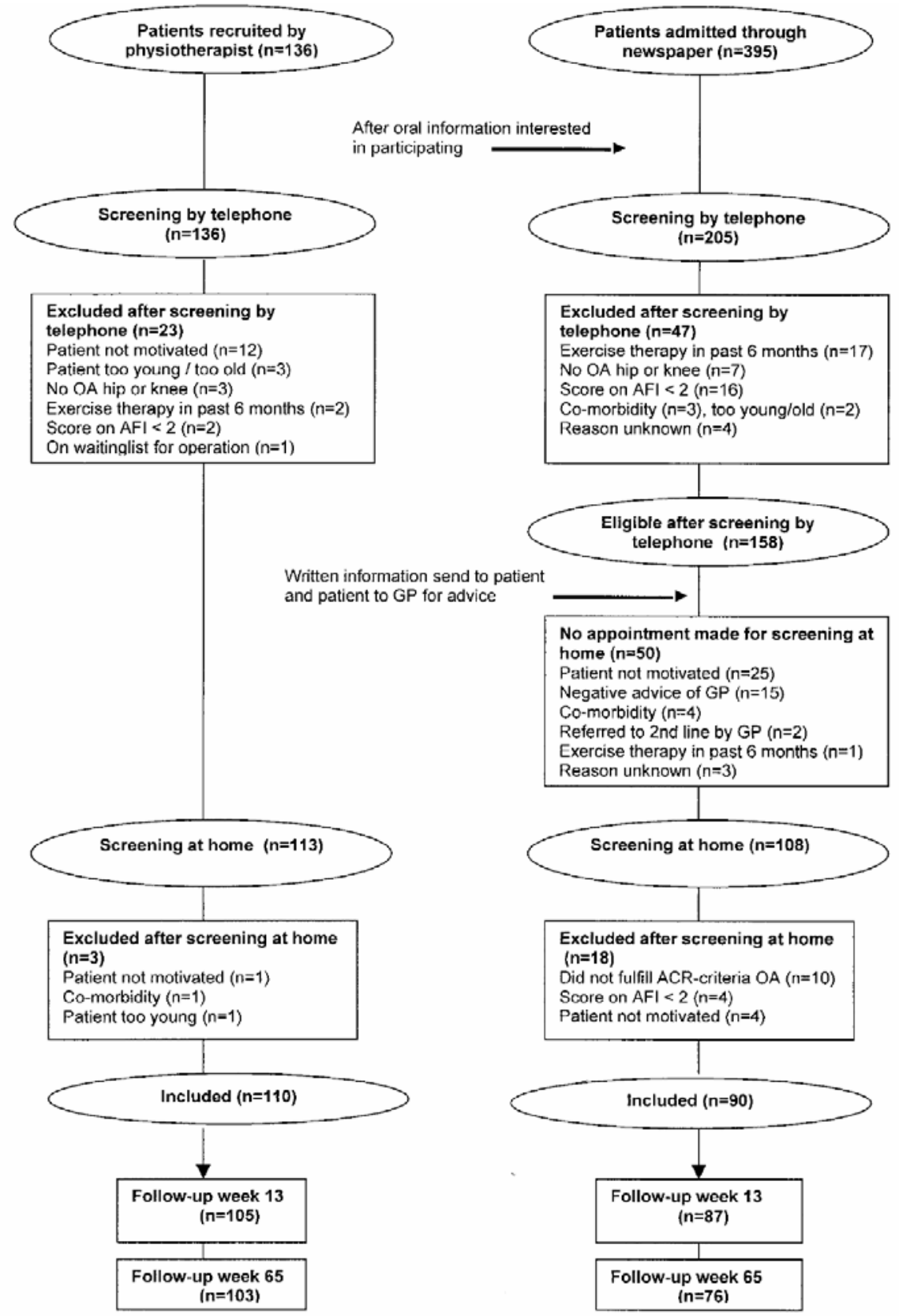

Figure 1. Flow chart of inclusion procedure for each recruitment strategy. OA = osteoarthritis: AFI = Algofunctional Index: $\mathrm{GP}=$ general practitioner; $\mathrm{ACR}=$ American College of Rheumatology. 
Veenhof, C., Dekker, J., Bijlsma, J.W.J., Ende, C.H.M. van den

Influence of various recruitment strategies on the study population and outcome of a randomized

controlled trial involving patients with osteoarthritis of hip or knee.

Arthritis and Rheumatism: 53, 2005, nr. 3, p. 375-382

\begin{tabular}{|c|c|c|c|}
\hline Characteristics & $\begin{array}{c}\text { Physiotherapist } \\
\mathrm{n}=110\end{array}$ & $\begin{array}{c}\text { Newspaper } \\
\mathrm{n}=\mathbf{9 0}\end{array}$ & $P$ \\
\hline Female, n (\%) & $81(74)$ & $73(81)$ & 0.21 \\
\hline Age, mean $\pm S D$ years & $64.9 \pm 7.9$ & $64.6 \pm 7.9$ & 0.76 \\
\hline Location of OA, n (\%) & & & $<0.01$ \\
\hline Knee & $74(67)$ & $56(62)$ & \\
\hline Hip & $33(30)$ & $17(19)$ & \\
\hline Both & $3(3)$ & $17(19)$ & \\
\hline \multicolumn{4}{|l|}{ Affected side $\mathrm{OA}, \mathrm{n}(\%)$} \\
\hline Knee $(\mathrm{n}=150)$ & & & 0.04 \\
\hline 1 side & $49(64)$ & $34(47)$ & \\
\hline 2 sides & $28(36)$ & $39(53)$ & \\
\hline Hip $(n=70)$ & & & 0.23 \\
\hline 1 side & $28(78)$ & $22(65)$ & \\
\hline 2 sides & $8(22)$ & $12(35)$ & \\
\hline Duration of symptoms of knee, years $(n=148), n(\%)$ & & & $<0.01$ \\
\hline$<1$ & $27(36)$ & $6(8)$ & \\
\hline $1-5$ & $23(30)$ & $28(39)$ & \\
\hline$>5$ & $26(34)$ & $38(53)$ & \\
\hline Duration of symptoms of hip, years $(n=70), n(\%)$ & & & $<0.01$ \\
\hline$<1$ & $13(36)$ & $2(6)$ & \\
\hline $1-5$ & $14(39)$ & $16(47)$ & \\
\hline$>5$ & $9(25)$ & $16(47)$ & \\
\hline \multicolumn{4}{|l|}{ Radiographic evidence OA, Kellgren $\geq 2(\mathrm{n}=146)$} \\
\hline Knee $(\mathrm{n}=101), \mathrm{n}(\%)$ & $26(52)$ & $31(61)$ & 0.37 \\
\hline Hip $(n=51), n(\%)$ & $26(90)$ & $21(96)$ & 0.45 \\
\hline Comorbidity, n (\%) & & & 0.9 \\
\hline None & $35(33)$ & $32(36)$ & \\
\hline 1 & $35(33)$ & $17(19)$ & \\
\hline$\geq 2$ & $37(35)$ & $39(44)$ & \\
\hline Body mass index, mean $\pm S D$ & $28.9 \pm 4.5$ & $28.0 \pm 4.4$ & 0.17 \\
\hline Education, $\leq$ high school, n (\%) & $85(78)$ & $48(53)$ & $<0.01$ \\
\hline
\end{tabular}

\begin{tabular}{|c|c|c|c|}
\hline & $\begin{array}{c}\text { Physiotherapist } \\
\mathrm{n}=110\end{array}$ & $\begin{array}{c}\text { Newspaper } \\
\mathrm{n}=\mathbf{9 0}\end{array}$ & $P$ \\
\hline \multicolumn{4}{|l|}{ Severity of pain } \\
\hline At assessment (VAS) & $4.5 \pm 2.5$ & $3.4 \pm 2.7$ & 0.04 \\
\hline Past week (VAS) & $5.8 \pm 2.1$ & $5.3 \pm 2.3$ & 0.14 \\
\hline Subscale pain (WOMAC) & $9.3 \pm 3.0$ & $8.4 \pm 3.4$ & 0.049 \\
\hline Stiffness (WOMAC) & $3.9 \pm 1.7$ & $3.9 \pm 1.5$ & 0.91 \\
\hline \multicolumn{4}{|l|}{ Tiredness (VAS) } \\
\hline At assessment & $4.6 \pm 2.4$ & $3.4 \pm 2.6$ & $<0.01$ \\
\hline Past week & $5.3 \pm 2.2$ & $4.7 \pm 2.5$ & 0.08 \\
\hline \multicolumn{4}{|l|}{ Physical function } \\
\hline Subscale physical function (WOMAC) & $32.5 \pm 13.8$ & $31.5 \pm 10.7$ & 0.59 \\
\hline 5-meter walking time & $5.0 \pm 1.6$ & $4.5 \pm 0.9$ & $<0.01$ \\
\hline Physical activity, min/week (SQUASH) & $1,748 \pm 1,170$ & $1,665 \pm 1,019$ & 0.60 \\
\hline
\end{tabular}

\begin{tabular}{|lccc|}
\hline \multicolumn{4}{|c|}{ Table 3. Psychosocial variables of the study population at baseline } \\
\hline & $\begin{array}{c}\text { Physiotherapist } \\
\mathbf{n}=\mathbf{1 1 0}\end{array}$ & $\begin{array}{c}\text { Newspaper } \\
\mathbf{n}=\mathbf{9 0}\end{array}$ & $P$ \\
\hline & & & \\
\hline Pain Coping Inventory & $2.3 \pm 0.5$ & $2.3 \pm 0.6$ & 0.87 \\
Pain transformation & $2.4 \pm 0.6$ & $2.4 \pm 0.5$ & 0.99 \\
Distraction & $2.2 \pm 0.5$ & $2.3 \pm 0.5$ & 0.16 \\
Reduction demands & $1.7 \pm 0.5$ & $1.8 \pm 0.5$ & 0.21 \\
Retreating & $1.7 \pm 0.4$ & $1.8 \pm 0.5$ & 0.39 \\
Worrying & $2.2 \pm 0.5$ & $2.3 \pm 0.5$ & 0.05 \\
Resting & & & \\
Locus of Control & $21.3 \pm 5.6$ & $20.1 \pm 5.4$ & 0.12 \\
Internal health locus of control & $19.2 \pm 5.6$ & $17.5 \pm 5.1$ & 0.03 \\
Powerful others health locus of control & $19.4 \pm 6.2$ & $19.2 \pm 5.5$ & 0.79 \\
Chance health locus of control & $20.0 \pm 8.5$ & $20.2 \pm 8.6$ & 0.86 \\
Social support & & & \\
\hline * Values presented as mean \pm SD. & & & \\
\hline
\end{tabular}


Veenhof, C., Dekker, J., Bijlsma, J.W.J., Ende, C.H.M. van den

Influence of various recruitment strategies on the study population and outcome of a randomized controlled trial involving patients with osteoarthritis of hip or knee.

Arthritis and Rheumatism: 53, 2005, nr. 3, p. 375-382

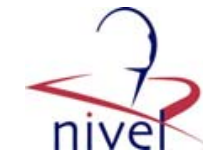

\begin{tabular}{|c|c|c|c|c|}
\hline Outcome measure & $\begin{array}{c}\text { PT group } \\
\text { improvement } \\
\text { mean } \pm \text { SD }\end{array}$ & $\begin{array}{l}\mathrm{NP} \text { group } \\
\text { improvement } \\
\text { mean } \pm \mathrm{SD}\end{array}$ & $\begin{array}{c}\text { Difference } \\
\text { between groups, } \\
\text { NP - PT mean }(95 \% \mathrm{CI})\end{array}$ & $\begin{array}{c}\text { Adjusted difference } \\
\text { between groups, } \\
\text { NP - PT mean }(95 \% \mathrm{CI})+\end{array}$ \\
\hline \multicolumn{5}{|l|}{ Week 13} \\
\hline $\mathrm{n}$ & 105 & 87 & & \\
\hline \multicolumn{5}{|l|}{ Pain } \\
\hline Pain at assessment (VAS) & $-0.75 \pm 2.8$ & $-0.28 \pm 2.7$ & $0.48(-0.3,1.3)$ & $-0.09(-0.8,0.6)$ \\
\hline Pain past week (VAS) & $-1.43 \pm 2.6$ & $-0.90 \pm 2.7$ & $0.53(-0.2,1.3)$ & $0.42(-0.2,1.1)$ \\
\hline Subscale pain WOMAC & $-2.70 \pm 3.3$ & $-1.76 \pm 3.0$ & $0.94(0.03,1.8) \neq$ & $0.47(-0.4,1.3)$ \\
\hline Physical function WOMAC & $-6.60 \pm 9.5$ & $-5.17 \pm 9.9$ & $1.43(-1.4,4.4)$ & $0.95(-1.9,3.8)$ \\
\hline Global perceived effect§ & $40(38)$ & $34(39)$ & $0.96(0.5,1.7)$ & $0.8(0.4,1.5)$ \\
\hline \multicolumn{5}{|l|}{ Week 65} \\
\hline n & 103 & 76 & & \\
\hline \multicolumn{5}{|l|}{ Pain } \\
\hline Pain at assessment (VAS) & $-1.23 \pm 3.2$ & $-0.18 \pm 2.6$ & $1.04(0.2,1.9) \ddagger$ & $0.16(-0.6,0.9)$ \\
\hline Pain past week (VAS) & $-2.04 \pm 2.9$ & $-1.72 \pm 2.6$ & $0.32(-0.5,1.2)$ & $-0.09(-0.8,0.6)$ \\
\hline Subscale pain WOMAC & $-3.94 \pm 3.8$ & $-3.00 \pm 3.3$ & $0.93(-0.1,2.0)$ & $0.22(-0.8,1.3)$ \\
\hline Physical function WOMAC & $-8.37 \pm 12.9$ & $-6.83 \pm 12.9$ & $1.53(-2.4,5.5)$ & $0.12(-3.6,3.8)$ \\
\hline Global perceived effect§ & $54(54)$ & $37(50)$ & $1.17(0.6,2.1)$ & $0.92(0.5,1.8)$ \\
\hline \multicolumn{5}{|c|}{$\begin{array}{l}\text { * Change scores (posttest at } 13 \text { and } 65 \text { weeks - pretest at baseline) with standard deviations. Mean and adjusted difference between groups with } 95 \% \\
\text { confidence interval ( } 95 \% \mathrm{CI} \text { ). Negative signs indicate improvement. PT = physiotherapy; NP = newspaper; VAS = visual analog scale; WOMAC = } \\
\text { Western Ontario and McMaster Universities Osteoarthritis Index. } \\
+ \text { Adjusted for following baseline variables: duration of symptoms, location of osteoarthritis, VAS pain at assessment, and baseline score on the specific } \\
\text { outcome measure. } \\
\text { † Difference between groups, } P \leq 0.05 \text {. } \\
\text { \$ Percentage improved; calculated with odds ratio. }\end{array}$} \\
\hline
\end{tabular}

